\title{
Ueber die Zusammensetzung des chlorsauren Baryts und Strontians;
}

von Aug. Souchay.

1. Chlorsaurer Baryt. - Chlorsaurer Baryt, nach der Methode von Böttger dargestellt, in schönen grofsen Krystallen erhalten, hatte die Zusammensetzung $\mathrm{BaO}, \mathrm{ClO}_{5}+$ aq., wie diefs Wächter schon angiebt.

1,7287 Grm. lufttrockenes Salz gaben 1,2417 $\mathrm{BaO}, \mathrm{SO}_{3}$, entsprechend 47,18 pC. BaO. Obige Formel verlangt 47,42 pC. BaO.

2. Chlorsaurer Strontian. - Chlorsaurer Baryt wurde mit der berechneten Menge Schwefelsäure so zersetzt, dafs die Schwefelsäure schwach vorwaltete. Die so bereitete reine Chlorsäure wurde mit kohlensaurem Strontian im Ueberschufs versetzt, filtrirt und die Lösung des chlorsauren Strontians bei mittlerer Temperatur, über Schwefelsäure, unter dem Exsiccator verdunstet. - Es wurden körnige kleine Krystalle erhalten, die an der Luft rasch zerflossen. - Ein Theil derselben zwischen Fliefspapier geprefst ergab die folgende Zusammensetzung : $0,5685 \mathrm{Grm}$. in Wasser gelöst, mit Ammon und kohlensaurem Ammon gefällt, gaben 0,2424 Grm. $\mathrm{SrO}, \mathrm{CO}_{2}$ $=29,95$ pC. SrO. Die Formel SrO, $\mathrm{ClO}_{5}+5$ aq. verlangt $30,14 \mathrm{pC}$. SrO. Es stimmt diefs nicht mit der Angabe von Wächter, der das Salz wasserfrei fand; Chenevix fand $28 \mathrm{pC}$. Wasser im chlorsauren Strontian.

Das Salz löste sich leicht in Wasser, etwas schwieriger löste es sich in Weingeist.

Die wässerige Lösung gab mit Kieselflufssäure und Alkohol versetzt keinen Niederschlag. Mit arseniger Säure und Ammon versetzt ebenfalls nicht; also war das Präparat von Baryt und Kalk frei. 